\title{
ANALISA KELAYAKAN USAHA PENANGKAPAN IKAN MENGGUNAKAN ALAT TANGKAP PAYANG (SEINE NET) DI PANTAI MALABERO KOTA BENGKULU
}

\author{
Rusdi Andika Amry, Person Pesona Renta, Eko Nofridiansyah \\ Program Studi IImu IImu Kelautan Universitas Bengkulu \\ Email: rusdiandhikaamry@gmail.com
}

Received August 2017, Accepted September 2017

\begin{abstract}
ABSTRAK
Pukat payang merupakan salah satu alat tangkap yang digunakan nelayan Pantai Malabero. Alat tangkap ini masih digunakan meskipun menghasilkan keuntungan yang kecil dikarekan biaya operasional yang besar dah hasil tangkapan yang sedikit. Tujuan dari penelitian ini adalah untuk menganalisa tingkat kelayakan usaha penangkapan dengan alat tangkap payang (Seine Net). Penelitian ini dilakukan dengan menggunakan metode pengumpulan data (observasi, wawancara, dokumentasi) dan metode analisis data (analisis aspek teknis dan analisis aspek finansial). Manfaat dari hasil penelitian ini diharapkan dapat menjadi informasi dan acuan bagi pihak-pihak yang akan mengembangkan usaha penangkapan ikan dengan alat tangkap payang di pantai Malabero khususnya dan di Kota Bengkulu umumnya. Hasil analisis finansial usaha penangkapan ikan dengan alat tangkap Payang di Pantai Malabero Kota Bengkulu adalah Nilai NPV $>0$ (Rp 147.448.741-), Net B/C ratio $>1(3,2)$, IRR $>19,25 \%(35,48 \%)$ dan $\mathrm{PP}<10$ tahun (1,0 tahun), maka usaha penangkapan ikan menggunakan alat tangkap payang di Pantai Malabero Kota Bengkulu layak untuk dikembangkan secara finansial.
\end{abstract}

Kata kunci: Analisa Kelayakan Usaha,Pantai Malabero, Payang (Seine Net)

\begin{abstract}
Seine net is one of the fishing gear used by Malabero Beach fishermen. These fishing gear is still used even though it produces small profits at the expense of large operational costs and small catches. The purpose of this research is to analyze the feasibility level of catching business with Seine $\mathrm{Ne}$ ). This research was conducted by using data collection method (observation, interview, documentation) and method of data analysis (Technical aspect analysis and financial aspect analysis). The benefits of the results of this study is expected to be information and reference for the parties who will develop a fishing business with fishing gear in Malabero beach in particular and in the city of Bengkulu generally. The result of
\end{abstract}


financial analysis of fish catching business with Payang fishing gear at Malabero Beach of Bengkulu City is NPV value $>0$ (Rp 147.448.741-), Net $B / C$ ratio $>1$ (3,2), IRR> 19,25\% (35, 48\%) and $P P<10$ years (1.0 years), the fishing effort using the fishing gear at Malabero Beach Kota Bengkulu is feasible to be developed financially.

Keywords: Business Feasibility Analysis, Seine Net, Malabero Beach.

\section{PENDAHULUAN}

Kota Bengkulu merupakan salah satu kota yang berada di wilayah pesisir, sehingga secara tidak langsung banyak masyarakat Kota Bengkulu yang berprofesi sebagai nelayan khususnya yang berada disekitar pantai Malabero. Pantai Malabero merupakan pantai yang terletak di Kelurahan Malabero dengan mayoritas penduduknya berprofesi sebagai nelayan. Alat tangkap di Provinsi Bengkulu berjumlah 17.267 dengan 39 jenis alat dan jumlah kapal 3.799 dengan hasil tangkapan yang sangat bervariasi pula dari mulai jenis demersal sampai ke pelagis besar seperti tuna (Dinas Kelautan dan Perikanan Provinsi Bengkulu, 2011). Salah satu alat tangkap yang banyak digunakan nelayan Pantai Malabero adalah pukat payang atau istilah nelayan sekitar menyebutnya pukek rabok. Terdapat sekitar 20 unit perahu dan alat tangkap yang digunakan nelayan pantai Malabero, bisa dikatakan mayoritas nelayan pantai Malabero menggunakan alat tangkap payang.

Alat tangkap payang merupakan alat tangkap modifikasi yang menyerupai trawl kecil yang dioperasikan di permukaan perairan. Dari segi konstruksi alat tangkap tersebut hampir mirip dengan lampara, yang membedakan adalah tidak digunakannya otter board dalam pengoperasiannya. Payang juga mempunyai alat bantu yaitu rumpon.

Untuk hasil tangkapan ikan, nelayan di Pantai Malabero mengaku dalam mendapatkan hasil tangkapannya relatif sedikit karena biaya operasional yang harus dikeluarkan lumayan besar sehingga mengurangi pendapatanya. Tetapi hingga saat ini, Payang (Seine net) masih digunakan sebagai alat tangkap oleh para nelayan di Pantai Malabero. Oleh karena itu penelitian ini akan dilakukan untuk menganalisis kelayakan usaha dari usaha penangkapan ikan menggunakan alat tangkap payang untuk melihat aspek teknis dan aspek finansial.

\section{MATERI DAN METODE}

\section{Waktu dan Tempat Penelitian}

Penelitian ini dilakukan selama dua bulan yaitu pada bulan OktoberDesember 2016 di Pantai Malabero Kota Bengkulu.

\section{Metode Pengumpulan Data}

Penelitian ini dilakukan dengan menggunakan metode survei. Ruang lingkup kegiatan penelitian adalah observasi dengan pengamatan 
langsung objek di lingkungan nelayan (Arikunto, 2013), wawancara untuk pengambilan data atau memperoleh keterangan dengan cara mengadakan tanya jawab serta bertatap muka secara langsung (Sugiyono, 2009) dan dokumentasi untuk mengumpulkan data meliputi pengambilan foto, pengumpulan artikel dari surat kabar, majalah, dan buletin serta menyelidikinya (Nazir, 2002) dan pengambilan sampel sebanyak 10 responden yaitu 10 orang pada usaha penangkapan ikan dengan alat tangkap payang di Pantai Malabero Kota Bengkulu.

\section{Metode Analisis Data}

Analisis data yang dipakai adalah analisis aspek teknis dan analisis aspek finansial. Aspek teknis meliputi ukuran kapal, mesin kapal dan anak buah kapal. Perhitungan Gross Tonnage (GT) menggunakan rumus dari Nomura dan Yamazaki tahun 1977. Sedangkan aspek finansial meliputi Net Present Value (NPV), Benefit Cost Ratio (B/C Ratio), Internal Rate of Return (IRR) dan Payback Period (PP). Perhitungan aspek finansial menggunakan rumus dari Gray dkk. tahun 1992.

\section{HASIL DAN PEMBAHASAN}

\section{Analisis Aspek Teknis}

\section{Deskripsi Perahu}

Perahu adalah alat yang digunakan untuk menuju daerah penangkapan dan membantu pengoperasian alat tangkap payang. Perahu di Pantai Malabero terbuat dari bahan kayu (papan) dan bercadik dua batang bambu di kiri dan kanan perahu.

\section{Deskripsi Alat Tangkap Payang (Seine Net)}

Pukat payang (Seine net) adalah alat yang digunakan nelayan Pantai Malabero untuk menangkap ikan yang terbuat dari bahan jaring berbahan PVC (Polyvinileclorine), berbentuk seperti kantong bagian badan jaring atau kepala jaring adalah 24 meter. Ukuran mesh size pada bagian badan jaring yang berbeda-beda yaitu mulai dari $2,54 \mathrm{~cm}-7,62 \mathrm{~cm}, 2,54 \mathrm{~cm}$ (ukuran benang D6), 5,08 cm (ukuran benang D9), dan untuk 7,62 cm (ukuran benang D18).

Payang yang digunakan nelayan Pantai Malabero terdiri dari beberapa bagian yaitu:

1. Sayap, payang mempunyai 2 bagian sayap yaitu bagian sayap kiri dan bagian sayap kanan. Kontruksi bagian bagian atas dan bawah dari sayap berbeda ukuran dan bahan sayap terbuat dari bahan PE.

2. Kantong (cod end) adalah merupakan tempat berkumpulnya ikan yang terjaring.

3. Tali ris atas dan bawah, berfungsi untuk dipakai memasang atau menggantungkan badan jaring. Pemasangan tali ris bagian atas dipasang di bawah tali pelampung sedangkan tali ris bawah dipasang di atas tali pemberat.

4. Tari penarik (Selambar).

5. Pelampung, berfungsi untuk menghasilkan gaya apung pada Payang. 
6. Tali pelampung, adalah tali yang digunakan untuk memasang pelampung.

7. Tali pemberat, adalah tali yang dipakai untuk memasang pemberat.

8. Pemberat, berfungsi untuk menghasilkan gaya berat pada Payang.

\section{Metode Operasi Penangkapan Payang}

Penangkapan dengan jaring payang dapat dilakukan baik pada malam maupun siang hari. Untuk malam hari terutama pada hari-hari gelap (tidak dalam keadaan terang bulan) dengan menggunakan alat bantu lampu petromaks (kerosene pressure lamp). Sedang penangkapan yang dilakukan pada siang hari menggunakan alat bantu rumpon/payaos (fish aggregating device) atau kadang kala tanpa alat bantu rumpon, yaitu dengan cara menduga-duga ditempat yang dikira banyak ikan atau mencari gerombolan ikan. Kalau gerombolan ikan yang diburu tadi kebetulan tongkol dalam penangkapan ini disebut oyokan tongkol. Penggunaan rumpon untuk alat bantu penangkapan dengan payang meliputi 95\% lebih. Payang biasanya dioperasikan di lapisan permukaan air (water surface), dengan tujuan menangkap ikan pelagis yang membentuk kelompok atau schooling.

\section{Persiapan Alat}

Sebelum operasi dimulai semua peralatan dan perbekalan harus dipersiapkan dengan teliti. Jaring harus disusun di atas perahu dengan memisahkan antara pemberat dan pelampung supaya mudah menurunkannya dan tidak kusut. Penyusunan payang diatas perahu penangkapan ikan disesuaikan dengan susunan peralatan di atas perahu sehingga dengan demikian payang dapat disusun di atas perahu.

\section{Waktu Penangkapan dan Daerah Penangkapan Ikan}

Payang dapat dioperasikan baik pada siang maupun malam hari. Pengoperasian payang pada malam hari terutama dilakukan saat keadaan tidak terang bulan dan menggunakan alat lampu petromaks. Pengoperasian payang pada siang hari dapat menggunakan rumpon sebagai alat bantu pengoperasian. Nelayan payang yang ada di Pantai Malabero melakukan penangkapan ikan di ruang lingkup perairan Kota Bengkulu sejauh 10-35 mil dengan melakukan pencarian fishing ground pada waktu pagi hari sampai siang hari hari selama 10-12 jam dalam satu trip operasi penangkapan.

\section{Penurunan Alat}

Penurunan jaring dimulai (setting), tali selambar kiri (yang ujungnya diberi pelampung tambahan jerigen 30 liter dilepas dari tumpukan jaring kepermukaan air. setelah itu diturunkan pelampung disusul bersamaan penurunan jaring, dan pemberat Sehingga bagian jaring mengikut turun, kapal bergerak terus sampai selesai sayap kiri disusul ujung belakang 
kantong dilempar keluar (supaya tidak kusut ) disusul dengan penurunan badan dan bossom jaring, kapal berjalan terus sambil membentuk lingkaran yang diikuti penurunan jaring bagian sayap kanan, sampai di ujung tali selambar kiri (depan yang telah diturunkan pertama kali), diujung tali selambar tersebut jangkar pengait dilemparkan ke dasar. Soaking time dalam pengoperasian payang tergantung proses pengoperasiannya, jika menggunakan lampu atau rumpon membutuhkan waktu menunggu (soaking time) ikan berkumpul disekitar rumpon, namun jika tidak menggunakan rumpon atau lampu melainkan dengan cara menduga-duga daerah yang banyak terdapat gerombolan ikan, maka tanpa soaking time. tingkat keberhasilan dalam peroses ini adalah kecepatan melingkari gerombolan ikan.

\section{Penaikan Alat dan Pengambilan Ikan}

Penarikan jaring (hauling) dilakukan dari sisi lambung kapal atau buritan kapal tanpa menggunakan mesin bantu penangkapan (fishing machinery) dan kedudukan kapal berlabuh jangkar atau kedudukan kapal terapung (drifting), agar tidak terjadi gerakan mundur kapal yang berlebihan, diupayakan kapal bergerak maju dengan kecepatan kapal lambat, sesuai beban/kecepatan penarikan payang. Pengangkatan jaring (brailing) Hasil tangkapan diangkat menggunakan tangan ke atas kapal kemudian di kelompokkan berdasarkan spesies - spesiesnya masingmasing dan di masukkan ke lambung kapal sebagai tempat sementara sebelum berlayar ke darat.Urutan pengangkatan alat tangkap dimulai dari menaikkan pelampung tanda, tali selambar belakang, badan jaring, tali selambar muka dan terakhir pelampung tanda. Setelah alat tangkap dinaikkan kemudian melepaskan ikan yang tertangkap dari badan jaring dan menyimpan ikan pada box (tempat ikan).

\section{Hasil Tangkapan}

Dalam perikanan tangkap payang musim sangat mempengaruhi hasil tangkapan. Nelayan di Pantai Malabero mengenal tiga musim penangkapan yaitu musim pacakelik, musim sedang dan musim puncak. Pada saat melakukan penelitian hasil tangkapan dari tiga musim tersebut yaitu pada musim pacakelik hasil tangkapannya sangat rendah, pada waktu musim sedang hasil tangkapannya sedang, dan pada musim puncak hasil tangkapannya tinggi tetapi bila dilihat dari jenis ikan hasil tangkapan dari tiga musim tersebut, jenis ikan hasil tangkapan sama yaitu ikan Belato/selar, Gembolo, Bawal Hitam, Muncok, Tongkol, Sarai, dan Kembung. 
Tabel 1. Jenis, jumlah dan harga hasil tangkapan alat tangkap payang di Pantai Malabero pada setiap jenis ikan.

\begin{tabular}{clcc}
\hline No & \multicolumn{1}{c}{ Jenis } & $\begin{array}{c}\text { Jumlah Rata- } \\
\text { Rata Pertrip (Kg) }\end{array}$ & $\begin{array}{c}\text { Harga Satuan } \\
(\mathrm{Rp})\end{array}$ \\
\hline 1 & Selar (Selarcrumenophthalmus) & 4 & 30.000 \\
2 & Gembolo (Rastrelliger) & 3 & 45.000 \\
3 & $\begin{array}{l}\text { Bawal Hitam (Parastromateus } \\
\text { niger) }\end{array}$ & 2 & 45.000 \\
4 & Muncok & 5 & 20.000 \\
5 & Tongkol (Euthynnus affinis) & 5 & 30.000 \\
6 & Sarai (Rastrellige) & 3 & 40.000 \\
7 & Kembung (Rastrellige) & 3 & 45.000 \\
\hline Jumlah & 25 & & Rp. 255.000 \\
\hline Rata-Rata & 24 & & Rp. 36.429 \\
\hline
\end{tabular}

Berdasarkan Tabel 1 diatas, jumlah hasil tangkapan rata-rata pertrip yaitu $24 \mathrm{Kg}$, dengan harga jual rata-rata adalah Rp. 36.429 ,-

\section{Mesin Perahu}

Mesin perahu merupakan bagian yang sangat penting dari perahu yang berfungsi sebagai sarana penggerak. Mesin penggerak perahu Payang yang ada di Pantai Malabero adalah mesin disel yang berbahan bakar solar dan berkekuatan berbeda-beda seperti 26 PK merk Jiang Dong (JD). Mesin perahu terletak pada bagian tengah didalam badan perahu.

\section{Anak buah kapal}

Anak buah kapal adalah semua yang berada dan berkerja di kapal. Keterampilan ABK mempengaruhi pendapatan hasil tangkapan dimana pada saat proses penurunan alat tangkap (setting) dan pengangkatan (hauling) harus mempunyai tingkat kelincahan pada proses melakukan penangkapan. Jumlah ABK dalam satu kapal/perahu 10-11 orang termasuk juga tekong/kapten kapal. Masing-masing ABK mengoperasikan alat tangkap dan 1 orang merangkap tugas sebagai tekong atau kapten kapal yang mengendalikan kapal atau perahu pada saat melakukan penangkapan. 


\section{Sistem Bagi Hasil}

Sistem bagi hasil bisa kita lihat pada tabel 2 .

Tabel 2. Sistem Bagi Hasil

\begin{tabular}{llcccc}
\hline No & Jabatan/Profesi & Bagian & $\begin{array}{c}\text { Pendapatan } \\
\text { Pertrip (Rp) }\end{array}$ & $\begin{array}{c}\text { Pendapatan } \\
\text { Perbulan (Rp) }\end{array}$ & $\begin{array}{c}\text { Total } \\
\text { Pendapatan } \\
\text { Pertahun (Rp) }\end{array}$ \\
\hline 1 & Kapten & 3 & $34.926,75$ & $803.315,31$ & $9.639 .783,67$ \\
2 & ABK & 1 & $11.642,25$ & $267.771,77$ & $3.213 .261,22$ \\
3 & Kerja Pukat & 2 & $23.284,50$ & $535.543,54$ & $6.426 .522,45$ \\
4 & Tukang Mesin & 2 & $23.284,50$ & $535.543,54$ & $6.426 .522,45$ \\
5 & Benen & 2 & $23.284,50$ & $535.543,54$ & $6.426 .522,45$ \\
\hline
\end{tabular}

Sistem bagi hasil yang berlaku bagi nelayan pantai malabero kota Bengkulu yaitu menggunakan system bagi dua (maron) dari hasil tangkapan, antara lain satu bagian untuk pemilik kapal/juragan kapal dan satu bagian lagi untuk para ABK kapal dimulai dari Kapten, Anak Buah Kapal (ABK), Kerja Pukat, Tukang Mesin, dan yang terakhir untuk Benen. Hal ini sudah diterapkan dalam suatu kelompok nelayan berdasarkan tingkatan dan jabatannya. Dan untuk bagian masing-masing para $A B K$ kapal bisa kita lihat pada tabel diatas dimana untuk kapten mendapat 3 bagian/trip, Anak buah kapal (ABK) mendapat 1 bagian/trip, kerja pukat mendapat 2 bagian/trip, tukang mesin mendapat 2 bagian/trip, dan benen mendapat 2 bagian/trip. Hasil dari pendapatan masing-masing kapten dan kru kapal yaitu didapatkan dari hasil pendapatan bersih yang didapatkan setelah, mengeluarkan biaya-biaya operasional seperti solar (BBM) dan perbekalan (beras, lauk-pauk, kopi, gula, rokok, dan es balok), biaya perawatan kapal dan biaya perawatan alat tangkap, setelah menghitung semua biaya-biaya tersebut maka didapatkan pendapatan bersih.

\section{Analisis Aspek Finansial}

Analisis aspek finansial merupakan analisis untuk menentukan kelayakan usaha yang dijalankan, untuk mengukur kegiatan usaha yang dilakukan saat ini berhasil atau tidak. Analisis ini dapat digunakan untuk mengetahui besarnya keuntungan yang diperoleh dari suatu kegiatan yang dilakukan (Umar, 2003). Hasil penelitian menunjukan bahwa produksi ikan hasil tangkapan rata-rata pertrip di Pantai Malabero Kelurahan Malabero Kota Bengkulu sebesar $25 \mathrm{~kg}$ dan harga jual ikan

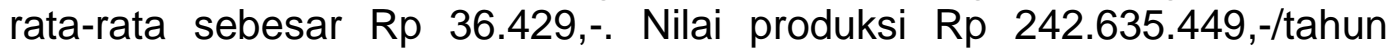
dengan rata-rata jumlah 231 trip/tahun dan menggunakan keredit bunga yang telah disepakati sebesar 19,25 \%. Pendapatan perahu merupakan 
permintaan tunai dari hasil penjualan ikan (Rp/Perahu/Tahun) dikurangi dari biaya tunai yang dikeluarkan (Rp/Perahu/Tahun). Biaya total dihitung dari biaya komponen biaya tetap dan tidak tetap/operasional ditambah upah/gaji ABK. Biaya komponen investasi terdiri dari perahu, alat tangkap, mesin dan biaya tetap terdiri dari perawatan perahu, perawatan alat tangkap, perawatan mesin, penyusutan perahu, penyusutan alat tangkap, penyusutan mesin serta biaya tidak tetap terdiri dari solar dan perbekalan.

\section{Biaya Investasi}

\section{Modal}

Modal yang diperlukan dalam usaha penangkapan ikan dengan alat tangkap payang rumpon yaitu sebesar Rp. 67.500 .000 yang terdiri dari kapal, mesin, dan alat tangkap payang. Uraian biaya investasi dalam usaha penangkapan ikan menggunakan alat tangkap payang di Pantai Malabero Kelurahan Malabero Kota Bengkulu dapat dilihat pada Tabel 3.

Tabel 3. Biaya rata-rata investasi yang dikeluarkan.

\begin{tabular}{cccc}
\hline No. & Biaya Investasi & $\begin{array}{c}\text { Umur Teknis Rata- } \\
\text { rata }\end{array}$ & $\begin{array}{c}\text { Harga Rata-rata } \\
\text { (Rp) }\end{array}$ \\
\hline 1. & Perahu & 10 & 30.000 .000 \\
2. & Alat Tangkap & 20 & 30.000 .000 \\
3. & Mesin & 3 & 7.500 .000 \\
\hline Jumlah & & & 67.500 .000 \\
\hline
\end{tabular}

Berdasarkan Tabel 3 menunjukan komponen biaya investasi yang meliputi perahu, alat tangkap, dan mesin dari seluruh responden yang berjumlah 10 responden memiliki umur teknis dan harga rata-rata yaitu :1). Umur teknis perahu rata-ratanya 10 tahun dengan harga $\mathrm{Rp} 30 . .000 .000,-$; 2). Umur teknis alat tangkap rata-ratanya 20 tahun dengan harga $\mathrm{Rp}$ $30.000 .000,-; 3)$. Umur teknis mesin rata-ratanya 3 tahun dengan harga Rp 7.500.000,-.

\section{Biaya tetap}

\section{Biaya Penyusutan dan Perawatan}

Biaya penyusutan dari hasil penelitian didapatkan bahwa umur ekonomis kapal pada umunya selama 10 tahun. Sedangkan untuk mesin berumur 3 tahun, dan alat tangkap berumur 20 tahun, serta alat bantu rumpon berumur 1 tahun. Biaya perawatan pada usaha penangkapan merupakan biaya-biaya yang dikeluarkan untuk kegiatan pemeliharaan faktor-faktor produksi dalam penangkapan ikan, sehingga alat-alat produksi tersebut dapat digunakan dengan maksimal. Biaya perawatan 
dalam usaha penangkapan payang rumpon yaitu berupa perawatan kapal, mesin jaring, dan penambahan rumpon. Perawatan kapal meliputi penambalan dan pengecetan sedangkan perawatan mesin meliputi ganti oli dan perawatan yang lain. Rata-rata biaya tetap untuk perawatan dan penyusutan usaha penangkapan ikan menggunakan alat tangkap payang di Pantai Malabero Kelurahan Malabero Kota Bengkulu dapat dilihat pada Tabel 4.

Tabel 4. Rata-rata biaya tetap (perawatan dan penyusutan) usaha penangkapan ikan menggunakan alat tangkap payang di Pantai Malabero Kota Bengkulu.

\begin{tabular}{llc}
\hline No & \multicolumn{1}{c}{ Biaya Tetap } & Harga/Tahun(Rp) \\
\hline 1 & Perawatan Perahu & 2.000 .000 \\
2 & Perawatan Alat Tangkap & 4.600 .000 \\
3 & Perawatan Mesin & 1.830 .000 \\
4 & Penyusutan Perahu & 3.000 .000 \\
5 & Penyusutan Alat Tangkap & 1.500 .000 \\
6 & Penyusutan Mesin & 2.500 .000 \\
7 & Rumpon & 500.000 \\
\hline & Jumlah & 15.930 .000 \\
\hline
\end{tabular}

Biaya tetap yaitu biaya yang harus dikeluarkan untuk seluruh sarana atau peralatan nelayan dalam merawat peralatan agar tetap baik dan berfungsi dengan baik saat dioperasikan dalam menangkap ikan, semua penyusutan peralatan akibat dari pengoperasian alat semua harus dihitung dan disesuaikan. Asumsi nelayan melakukan penangkapan dalam 1 tahun adalah 10 bulan. Sedangkan asumsi melakukan penangkapan dalam 1 bulan adalah 23 trip, maka asumsi nelayan melakukan penangkapan dalam 1 tahun adalah 231 trip. 


\section{Biaya Tidak Tetap}

\section{Biaya Operasional}

Biaya operasional adalah biaya yang dikeluarkan oleh nelayan untuk perbekalan selama operasi penangkapan. Biaya ini terdiri dari biaya perbekalan nelayan, dan biaya bahan bakar (BBM). Biaya perbekalan merupakan biaya untuk konsumsi selama operasi penangkapan seperti beras, lauk-pauk, air bersih, kopi, gula, rokok, dan es balok. Lama melaut untuk setiap trip masih sangat pendek, yaitu berkisar 11-12 jam atau setengah hari (one day fishing) karena hanya menggunakan perahu dengan kekuatan mesin 26 PK. Hal ini menyebabkan jangkauan operasioanal terbatas pada daerah pantai (zona 1), fishing ground (daerah penangkapan ikan terbatas) yaitu sejauh 10-35 Mil. Biaya tidak tetap atau biaya operasional meliputi biaya bahan bakar seperti: Solar dan perbekalan. Jangkauan tempat mencari ikan didekat pantai, sehingga biaya operasional dikeluarkan relatif sedikit.

Tabel 5. Rata-rata pertrip dan pertahun biaya tidak tetap atau biaya operasional nelayan payang di Pantai Malabero Kota Bengkulu.

\begin{tabular}{cccc}
\hline No. & Biaya Tidak Tetap & $\begin{array}{c}\text { Harga Rata- } \\
\text { rata/Trip }\end{array}$ & $\begin{array}{c}\text { Harga Rata- } \\
\text { rata/Tahun }\end{array}$ \\
\hline 1. & Solar & 125.000 & 28.875 .000 \\
2. & Perbekalan & 300.000 & 69.300 .000 \\
\hline & Jumlah & 425.000 & 98.175 .000
\end{tabular}

Hasil analisa kelayakan usaha penangkapan ikan dengan alat tangkap payang (seine net) di Pantai Malabero Kelurahan Malabero Kota Bengkulu 2016 secara finansial disajikan secara singkat pada Tabel 6 dan secara lengkap disajikan pada lampiran.

Tabel 6. Hasil analisa kelayakan usaha penangkapan ikan dengan alat tangkap payang (seine net) di Pantai Malabero Kelurahan Malabero Kota Bengkulu secara finansial.

\begin{tabular}{llll}
\hline \multicolumn{1}{c}{ Komponen } & \multicolumn{1}{c}{ Nilai } & \multicolumn{1}{c}{ Indikator } & \multicolumn{1}{c}{ Keterangan } \\
\hline NPV & 147.448 .741 & $>0$ & Layak \\
Net B/C Ratio & 3,2 & $>1$ & Layak \\
IRR & $35,48 \%$ & $>19,25 \%$ & Layak \\
Payback Period & 1,0 & $<10$ th & Layak \\
\hline
\end{tabular}


Tabel 6 Menunjukan bahwa usaha penangkapan ikan di Pantai Malabero kelurahan Malabero Kota Bengkulu layak secara finansial. Berdasarkan nilai NPV $>0($ Rp 147.448.741,- $)$, Net B/C Ratio $>1(3,2)$ dan IRR $>19,25 \%(35,48 \%)$ yang bernilai positif dan PP $<10$ tahun $(1,0$ tahun).

\section{Net Present Value (NPV)}

Nilai NPV pada usaha penangkapan payang rumpon yaitu sebesar Rp. 147.448.741 nilai NPV tersebut bernilai positif, hal ini menunjukkan bahwa usaha penangkapan payang rumpon layak untuk diteruskan.

\section{Net B/C Rattio}

Nilai B/C Ratio rata-rata usaha pada penangkapan payang rumpon adalah sebesar 3,2

Artinya setiap 1 rupiah biaya yang dikeluarkan akan menghasilkan penerimaan 3 rupiah 2 sen. Nilai tersebut menunjukkan B/C Ratio termasuk dalam kategori lebih dari satu sehingga dalam usaha penangkapan ikan tersebut dapat dilaksanakan atau dapat dijalankan. Berdasarkan Benefit Cost Ratio (B/C Ratio), suatu proyek atau kegiatan investasi dapat dikatakan layak bila diperoleh Net $B / C \geq 1$ dan dikatakan tidak layak bila diperoleh

Net $\mathrm{B} / \mathrm{C} \leq 1$. Sedangkan untuk analisis usaha penangkapan payang setelah dilakukan dalam perhitungan menggunakan rumus Net B/C Rattio sebesar 3,2. Maka usaha tersebut layak untuk di jalankan karena hasil Net B/C Ratio nya $>1$.

\section{Internal Rate of Return (IRR)}

Berdasarkan Internal Rate of Return (IRR) nilai usaha pada penangkapan payang rumpon adalah sebesar 35,48 \%. Nilai tersebut melebihi nilai discount factor yang bernilai 19,25 \%. Hal ini menunjukkan bahwa usaha penangkapan payang rumpon ini layak untuk dijalankan.

\section{Payback period (PP)}

Perhitungan PP pada usaha penangkapan payang rumpon adalah selama 1 tahun 0 bulan. Hal ini menunjukkan bahwa usaha penangkapan payang rumpon mempunyai tingkat pengembalian modalnya termasuk dalam kategori cepat karena PP dibawah 10 tahun.

Jika dibandingkan dengan penelitian sebelumnya, alat tangkap payang yang terdapat di Pelabuhan Perikanan Pantai Tawang Kabupaten Kendal lebih bagus dan produktif dibandingkan dengan alat tangkap payang yang berada dipantai Malabero Kota Bengkulu. Hal ini dikarenakan selain menggunakan payang rumpon, nelayan yang berada di Kabupaten Kendal ini juga menggunakan payang lampu. Untuk peneliti sendiri sudah meninjau kelapangan, untuk kawasan kota Bengkulu dan sekitarnya belum ada nelayan kota Bengkulu yang menggunakan payang 
lampu, dimana payang lampu tersebut dalam mendapatkan hasil tangkapannya lumayan banyak dibandingkan dengan payang rumpon berdasarkan penelitian yang ada di PPP Tawang Kabupaten Kendal.

Biaya investasi pada payang lampu ini memang memerlukan biaya yang besar dibandingkan dengan payang rumpon, dimana pada payang lampu harus menanmbahkan lampu yang banyak untuk penerangan agar memancing ikan-ikan berkumpul disekitar jaring, berbeda dengan payang rumpon pantai malabero yang hanya menggunakan daun pinang atau daun kelapa sebagai tempat wadah untuk mengumpulkan ikan, dan biaya yang dikeluarkan lebih sedikit dibandingkan dengan biaya yang dikeluarkan menggunakan payang lampu. Nelayan payang rumpon dan payang lampu yang berada di Kabupaten Kendal di PPP Tawang pada umumnya sangat tergantung dengan musim. Apabila sedang musim timur pada bulan april, mei, dan juni para nelayan sering menggunakan alat tangkap payang dengan alat bantu lampu, penangkapan dilakukan pada saat malam hari, sedangkan pada bulan september, oktober, dan november nelayan payang menggunakan alat bantu rumpon, penangkapan dilakukan pada pagi sampai sore hari.

Berbeda dengan nelayan yang berada di pantai Malabero kota Bengkulu, mereka melakukan penangkapan hanya dengan menggunakan payang rumpon baik siang maupun malam hari. Untuk hasil tangkapan nelayan yang berada di Kabupaten Kendal mengaku dalam mendapatkan hasil tangkapan lumayan banyak jika ditinjau dari aspek teknis, aspek ekonomi, dan aspek finansial. Selain itu hasil tangkapan nelayan payang yang berada di Kabupaten Kendal ini langsung dibawa ke pelabuhan perikanan agar langsung melakukan transaksi jual beli ikan ditempat pelalangan ikan. Ada sekitar empat TPI (Tempat Pelelangan Ikan) yang berada di Kabupaten Kendal yaitu, TPI Tawang, TPI Sendang Si kucing, TPI Tanggul Malang, dan TPI Bandengan. Terdapat sarana dan prasarana yang lengkap sehingga memudahkan para nelayan untuk menjual hasil tangkapannya. Berbeda dengan nelayan pantai Malabero Kota Bengkulu, sarana dan prasarana pelabuhan perikanannya belum ada, hanya masih sebatas tempat untuk menyandarkan kapal.

Berdasarkan hasil penelitian kelayakan usaha penangkapan ikan dengan alat tangkap payang berdasarkan PERMEN No. 2 tahun 2015 tentang larangan penggunaan alat tangkap pukat payang yaitu mengakibatkan menurunnya sumberdaya ikan dan mengancam kelestarian lingkungan sumberdaya ikan. Hasil tangkapan payang dinilai sebagai alat tangkap yang kurang selektif terhadap ikan tangkapan. Karena biota-biota yang matang gonad dan memijah dapat tertangkap oleh alat tangkap payang. Hal ini akan menyebabkan berkurangnya stok sumberdaya ikan (Panggabean $d k k, 2016$ ).

Dampak yang ditimbulkan dari Peraturan Menteri Kelautan dan Perikanan No.2/PERMEN-KP/2015 tentang Larangan Penggunaan Alat Tangkap Ikan Pukat Hela dan Pukat Tarik diantaranya memiliki dampak sosial. Dampak sosial yang ditimbulkan dapat berupa pengangguran. Peraturan Menteri ini menimbulkan pengangguran bagi anak buah kapal. Setiap satu kapal payang terdiri dari 10 anak buah kapal. Kota Bengkulu 
memiliki kapal payang sekitar unit, artinya dampak dari pelarangan alat payang akan merugikan lebih dari 200 orang yang kehilangan pekerjaan dalam satu kelurahan. Dampak sosial pelarangan alat tangkap payang memang akan berdampak besar terhadap banyak nelayan. Menurut data Kementerian Kelautan dan Perikanan, produksi perikanan tangkap di laut menurut alat tangkap Pukat payang pada tahun 2014 mencapai 690,629 ton. Berdasarkan hal tersebut, jika alat tangkap payang dilarang maka akan berdampak tidak hanya secara sosial, tapi juga ekonomi (Ermawati dan Zuliyati, 2015).

Hal yang menjadi permasalahan saat ini adalah pelarangan alat tangkap payang menimbulkan permasalahan baru khususnya bagi ekonomi nelayan. Keputusan untuk mewajibkan nelayan meninggalkan alat tangkap yang tidak ramah lingkungan tidak diiringi dengan upaya kompensasi penggantian alat tangkap tersebut. Biaya penggantian alat tangkap yang tinggi menjadi kendala nelayan untuk mengganti alat tangkap. Apalagi Menteri Susi mengatakan tidak akan memberikan uang bantuan terhadap nelayan dengan alat tangkap tidak ramah lingkungan. Namun pemerintah memberikan solusi yaitu tetap berupaya mengadakan pendampingan terhadap proses transisi penggantian alat tangkap.

Proses penggantian alat tangkap sebetulnya belum sepenuhnya siap. Dengan tidak adanya kompensasi bagi nelayan cantrang untuk mengganti alat tangkapnya, membuat nelayan harus mencari dana. Program pembiayaan dari perbankan untuk nelayan 10 GT ke atas belum siap. Skim kredit bukan khusus alat tangkap sehingga nelayan akan sulit untuk mengganti alat tangkap. Pemerintah seharusnya menjamin kepada nelayan untuk bisa mengganti alat tangkap tanpa memberatkan nelayan itu sendiri. Pemerintah juga perlu memberikan pelatihan kepada nelayan mengenai penggunaan teknologi alat tangkap yang lebih ramah lingkungan. Hingga saat ini, alasan nelayan belum mengganti alat tangkap payang diantaranya adalah karena nelayan masih menganggap bahwa alat tangkap payang adalah alat tangkap yang sesuai dengan ikan target yaitu ikan pelagis. Selain itu, nelayan juga kebingungan mencari alat tangkap yang baru, jika alat tangkap payang dilarang. Pasalnya nelayan pun tidak diberikan bantuan penggantian alat tangkap. sehingga terjadi pro dan kontra antara masyarakat, Di mana berdasarkan penelitian yang telah dilakukan secara finansial pukat payang merupakan alat tangkap yang layak untuk digunakan karena menguntungkan bagi perekonomian masyarakat pantai malabero kota Bengkulu.

\section{KESIMPULAN}

Hasil analisa kelayakan usaha penangkapan ikan dengan alat tangkap Payang di Pantai Malabero Kelurahan Malabero Kota Bengkulu secara finansial adalah nilai NPV Rp 147.448.741,-, Net B/C ratio 3,2, IRR $35,48 \%$ dan PP 1,0 tahun, maka usaha tersebut layak secara finansial. 


\section{DAFTAR PUSTAKA}

Arikunto, Suharsimi. 2013. Prosedur Penelitian : Suatu Pendekatan Praktik. Cetakan Kelimabelas. Jakarta : Rineka Cipta.

Dinas Kelautan dan Perikanan Provinsi Bengkulu. 2011. Profil Dinas Kelautan dan Perikanan. Provinsi Bengkulu.

Ermawati, N., Zuliyati. 2015. Dampak Sosial dan Ekonomi atas Peraturan Menteri Kelautan dan Perikanan Nomor 2/PERMENKP/2015, Makalah,dalam Prosiding Seminar Nasional Multi Disiplin IImu dan Call for PpersUNISBANK.

Gray, C., P. Simanjuntak, L.K. Sabur, P.F.L. Maspaitella, dan R.C.G. Varley. 1992. Pengantar Evaluasi Proyek. Gramedia. Jakarta. 314 p.

M. Nazir, 2002, Metodologi Penelitian, Jakarta:Gandisa Indonesia.

Nomura dan yamazaki. Fishing Techniques (1). Japan International Cooperation Agency. Tokyo. 1977.

Panggabean, S. A., Suhaidi., Leviza, J., Barus, U. M. 2016. Implementasi Peraturan Menteri Kelautan dan Perikanan No.2/PERMEN-KP/2015 tentang Larangan Penggunaan Alat Penangkap Ikan Pukat Hela (Trawls) dan Pukat Tarik (Seine Nets) terhadap Usaha Perikanan Tangkap oleh Nelayan di Sibolga. USU Law Journal.4 (4): 40-52.

Sugiyono, 2009. Memahami Penelitian Kualitatif. Alfabeta. Bandung.

Umar, H. 2003. Studi Kelayakan Bisnis. Edisi 3. PT Gramedia Pustaka Utama, Jakarta. 